\title{
Vantagens e oportunismo no relacionamento entre associados e cooperativa de laticínios
}

\author{
Advantages and opportunism relationship between associated and dairy \\ cooperative
}

\section{Ventajas y el oportunismo relación entre miembros y cooperativa lechera}

\section{Avantages et opportunisme relation entre les membres et laiterie cooperative}

\author{
Raquel Breitenbach ${ }^{1}$ \\ Janaína Balk Brandão ${ }^{2}$ \\ Marcelo Zorzan ${ }^{1}$
}

Recebido em 23/09/2016; revisado e aprovado em 15/04/2017; aceito em 15/04/2017

DOI: http://dx.doi.org/10.20435/inter.v18i2.1393

\begin{abstract}
Resumo: O objetivo do presente estudo foi identificar as vantagens do ponto de vista do agricultor/fornecedor que interferem na tomada de decisão quanto à comercialização do leite para uma cooperativa de laticínios, em detrimento de outras empresas processadoras, verificando o comportamento oportunista nas transações. Para além do preço, foi possível identificar que as vantagens da cooperativa se concentram na oferta de serviços como a assistência técnica e recompensas, como o retorno dos resultados financeiros e descontos em investimentos em genética.
\end{abstract}

Palavras-chave: cadeia de suprimentos; fornecedores; atributos das transações.

Abstract: The aim of this study was to identify the advantages of the farmer's point of view / supplier that interfere in the decision making regarding the marketing of milk for a dairy cooperative, to the detriment of other processing companies, checking opportunistic behavior in transactions. Apart from the price, it was possible to identify the cooperative advantages focus on the provision of services such as technical assistance and rewards, as the return of the financial results and discounts on investments in genetics.

Key words: supply chain; providers; attributes of transactions.

Résumé: Le but de cette étude était d'identifier les avantages du point de vue / fournisseur de l'agriculteur qui interfèrent dans la prise de décision concernant la commercialisation du lait pour une coopérative laitière, au détriment des autres entreprises de transformation, le contrôle des comportements opportunistes dans les transactions. Mis à part le prix, il a été possible d'identifier les avantages coopératifs se concentrer sur la fourniture de services tels que l'assistance technique et des récompenses, comme le retour des résultats financiers et des réductions sur les investissements dans la génétique.

Mots-clés: chaîne d'approvisionnement; fournisseurs; attributs des transactions.

Resumen: El objetivo de este estudio fue identificar las ventajas del punto de vista / proveedor del agricultor que interfieren en la toma de decisiones en relación con la comercialización de la leche para una cooperativa de productos lácteos, en detrimento de otras compañías de procesamiento, control de comportamiento oportunista en las transacciones. Aparte del precio, fue posible identificar las ventajas cooperativas se centran en la prestación de servicios tales como asistencia técnica y recompensas, como el retorno de los resultados financieros y descuentos en las inversiones en la genética.

Palabras clave: cadena de suministro; proveedores; los atributos de las transacciones.

\section{INTRODUÇÃO}

O Brasil é o sexto país maior produtor de leite, e a região sul é a maior região produtora do país, sendo o estado de Minas Gerais o principal produtor de leite em 2014, seguido pelo Rio Grande do Sul e em terceiro lugar o Estado do Paraná (UNITED STATES DEPARTMENT OF

\footnotetext{
$\overline{{ }^{1} \text { Instituto Federal }}$ de Educação, Ciência e Tecnologia do Rio Grande do Sul (IFRS), Sertão, Rio Grande do Sul, Brasil.

2 Universidade Federal do Pampa (UNIPAMPA), Bagé, Rio Grande do Sul, Brasil.
} 
AGRICULTURE [USDA], s.d.). Diante desse cenário, a cadeia produtiva do leite assume um espaço relevante dentro Rio Grande do Sul (RS). Em geral, o mercado de laticínios no RS é marcado pelo oligopsônio concorrencial. Ou seja, é constatada a concorrência entre empresas processadoras pela compra da matéria-prima produzida em nível de propriedade rural (BREITENBACH; SOUZA, 2015). Como consequência desse contexto/mercado, os agricultores migram de comprador de leite com maior frequência, buscando vantagens competitivas por parte das empresas processadoras (BREITENBACH; SOUZA, 2015).

Como forma de manter a competitividade, as agroindústrias precisam organizar a sua cadeia de suprimentos de forma eficiente, estreitando relações com os fornecedores, via de regra, adotando estruturas de governança híbridas. Assim, pondera-se que as organizações vão formar arranjos de forma eficiente com o objetivo de reduzir custos de transação, conforme preconiza a arcabouço teórico da Economia dos Custos de Transação (ECT). A ECT tem como suporte as seguintes categorias de análise: os pressupostos comportamentais dos agentes (racionalidade limitada e oportunismo); os atributos das transações (especificidade de ativos, frequência e incerteza); e os fatores exógenos relacionados ao ambiente organizacional e ambiente institucional onde se insere a organização (WILLIAMSON, 1989).

Assim, as questões que norteiam a presente pesquisa se concentram em: (1) Como se estabelecem as transações entre associado/fornecedor e a cooperativa de leite num mercado de concorrência para a aquisição da matéria-prima? (2) Existem vantagens das cooperativas diante de uma estrutura de mercado de fatores concorrencial?

Nesse sentido, o objetivo geral desta pesquisa foi identificar as particularidades capazes de fidelizar os fornecedores (produtores de leite), verificando se há comportamento oportunista por parte dos produtores. Para tanto, analisam-se as transações entre uma cooperativa de laticínios e seus fornecedores (agricultor/associado) num mercado de disputa entre empresas para aquisição da matéria-prima. Também se identificam os condicionantes nas decisões dos agricultores em comercializar a produção de leite com a cooperativa em detrimento de outras empresas processadoras.

\section{REFERENCIAL TEÓRICO}

A revisão teórica deste artigo tem o objetivo de citar as teorias que deram base à pesquisa em questão, auxiliando na busca dos dados a campo e na interpretação destes. Entretanto busca, também, verificar estudos semelhantes que já tenham sido realizados no âmbito desta pesquisa, procurando analisar o estado da arte desse tema empírico desde a perspectiva acadêmica. Primeiramente apresenta-se um breve conteúdo sobre a noção de cadeia produtiva e cadeia de suprimentos. Num segundo momento, tem-se um apanhado básico sobre estruturas de mercado e competitividade. Por fim, faz-se uma revisão em revistas científicas sobre a problemática da fidelidade dos agricultores em cooperativas.

\subsection{Cadeia produtiva e cadeia de suprimentos}

A cadeia produtiva do leite tem importância dentro do agronegócio. O início dessa cadeia se dá na produção de insumos, de que fazem parte empresas fabricantes de matéria-prima, equipamentos, crédito, serviços e pesquisa. O segundo elo refere-se à produção leiteira propriamente dita, envolvendo os produtores, os animais, o desenvolvimento genético, a qualidade e o preço 
de produtos. O terceiro elo é representado pela indústria, no qual fazem parte as empresas que transformam a matéria-prima, além das responsáveis pela logística do recolhimento do leite e distribuição dos produtos industrializados. O consumidor é o último elo dessa cadeia, é ele que adquire os produtos derivados do leite (GRAEF et al., 2009).

Dentro da cadeia produtiva, o elo 'agroindústria' é considerado neste estudo como elo focal, do qual partem as análises junto com a perspectiva do elo 'fornecedor'. Para Arbage (2004), a cadeia de suprimentos, de forma geral, pode ser caracterizada por três fluxos entre os agentes: fluxo de produtos; fluxo de recursos; e fluxo de informações. O fluxo de produtos procura atender, da melhor forma, a necessidade dos consumidores. O fluxo de recursos faz o caminho inverso, estando relacionado com a contrapartida monetária paga pelos produtos ou serviços. Já o fluxo de informações possui como característica ser bidirecional.

Ilustrando a complexidade envolta numa cadeia de suprimentos, Ballou (2004) apresenta um esquema do que ele chama de escopo da cadeia de suprimento moderna. Nesse esquema apresentado na Figura 1, o autor demonstra que, além dos fornecedores e clientes diretos de uma empresa, a cadeia possui os fornecedores dos fornecedores imediatos e os clientes dos clientes imediatos, chegando às fontes de matéria-prima e aos consumidores finais.

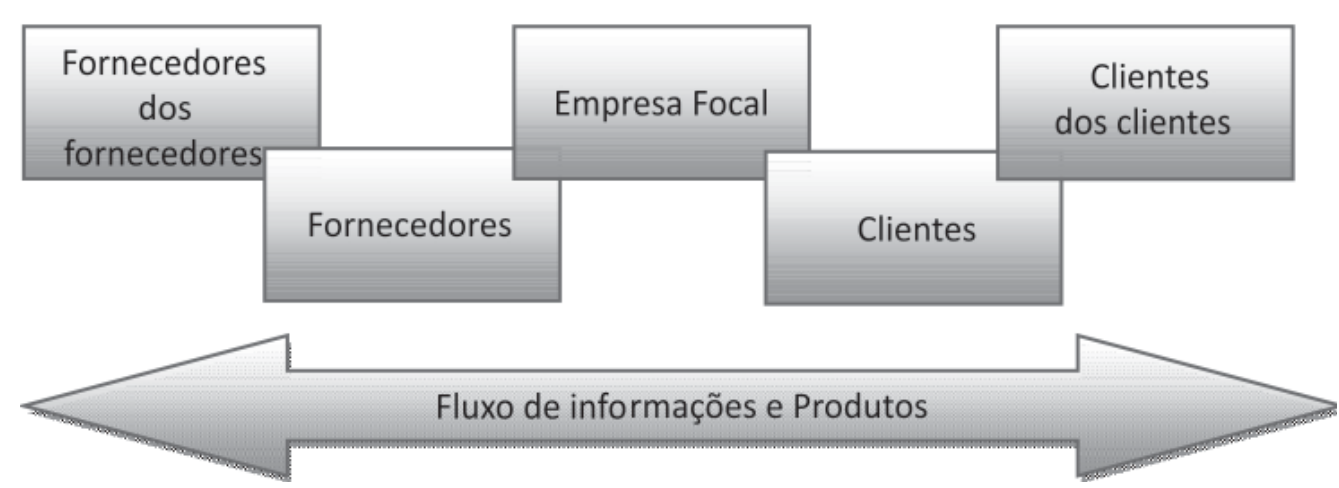

Figura 1 - Escopo da cadeia de suprimento moderna.

Fonte: Adaptado de Ballou (2004).

Como ponto relevante na Gestão da Cadeia de Suprimentos (GCS), destaca-se a necessidade de haver sintonia entre o fluxo de informações e a coordenação ao longo de toda cadeia de suprimentos. Se a informação for distorcida ou insuficiente, os esforços de coordenação podem ser prejudicados, considerando que a sinergia necessária não será atingida, impedindo que as engrenagens dos elos se encaixem perfeitamente (BRANDÃO, 2011). Esse atrito, no longo prazo, poderá comprometer o funcionamento do sistema.

Outra contribuição significativa, obtida através da utilização dessa metodologia, no ambiente competitivo, está relacionada à criação de uma cadeia de valor, na qual a competição entre as empresas ultrapassa o nível empresarial, atingindo um patamar menos tangível, ligado aos relacionamentos obtidos, mais difíceis de serem imitados (BRANDÃO, 2011). Ou seja, a competição ultrapassa o nível de empresas, atingindo o plano de valores. Beth et al. (2008), destacam que os desafios para o GCS não são fáceis. Os autores salientam que pessoas e relacionamentos estão na pauta contemporânea. Para Beth et al. (2008), a criação de alianças eficazes entre empresas é um assunto complicado porque, historicamente, os gerentes de compra são recompensados 
por espremerem seus fornecedores a fim de obter os menores preços possíveis (uma prática que não favorece o cultivo de um relacionamento de longo prazo).

\subsection{Estruturas de mercado e competitividade na cadeia produtiva do leite}

A estrutura de mercado define-se como a característica organizacional de um determinado mercado, a qual apresenta as relações existentes entre vendedores e compradores. A comercialização do leite está ligada a uma estrutura de mercado denominada oligopsônio, o que indica que nesse processo existe uma grande quantidade de produtores, com intuito de vender seu produto e uma restrita proporção de compradores (MENDES; PADILHA JUNIOR, 2007).

Vasconcelos e Garcia (2006, p. 230) ilustram esse tipo de mercado:

Oligopsônio é o mercado em que há poucos compradores negociando com muitos vendedores. Por exemplo, a indústria de laticínios, em cada cidade existem dois ou três laticínios que adquirem a maior parte do leite dos inúmeros produtores rurais locais.

Assim, a formação de preço do leite é influenciada pela indústria, já que é ela que estabelece o preço que vai pagar aos produtores rurais pelo leite produzido. Os preços do leite são resultado das condições de oferta e demanda, então a variável mais relevante é o preço. Nesse modo, é o produtor que encontra maiores dificuldades quanto ao preço do produto, já que são os compradores que influenciam com forte predominância na formação do preço pelo fato de não ter muitos compradores do leite (MENDES; PADILHA JUNIOR, 2007).

Por competitividade entende-se como a habilidade da empresa em formular e programar estratégias concorrenciais que Ihe permitam cultivar, de forma duradoura, uma posição sustentável no mercado (ALBUQUERQUE, 1992). Quanto à competitividade na cadeia produtiva do leite no Brasil, constata-se que esta evoluiu muito ultimamente, e isso se deve a vários fatores, tais como a melhora na dieta dos animais, investimento em genética e em pesquisa, além da utilização de equipamentos específicos como os resfriadores a granel, ordenhadeiras canalizadas (CANZIANI, 2003). Outro fator muito importante foi o aumento do consumo de leite longa vida, o Ultra High Temperature (UHT) (CANZIANI, 2003).

\subsection{Relação cooperativa $x$ cooperado: a fidelidade $x$ infidelidade}

A proposta de incentivo à fidelidade é algo que pode gerar, somar e complementar um plano de benefícios aos cooperados (MÓGLIA et al., 2004). Entretanto deverá haver uma classificação dos cooperados quanto ao aspecto fidelidade - o quanto movimenta e dá preferência à cooperativa, isso poderá ser medido e controlado conforme a sua pontuação acumulada através das diversas operações comerciais: compra e entrega de produtos, da movimentação financeira e de seus negócios junto à cooperativa entre outras (MÓGLIA et al., 2004).

Conforme destaca Giarola (2011), a despeito da importância das cooperativas no cenário atual, essas organizações enfrentam dificuldades principalmente no que se refere à doutrina ou ideologia cooperativista. Um dos grandes problemas enfrentados pelas cooperativas é a questão da infidelidade dos cooperados, decorrente do duplo papel que ele possui na organização (GIAROLA, 2011). Isso porque o associado é, ao mesmo tempo, trabalhador e dono dos recursos produtivos, o que faz com que ele procure maximizar os resultados de sua própria unidade produtiva, mesmo que seja em detrimento da empresa cooperativa, já que é movido pelo princípio

INTERAÇÕES, Campo Grande, MS, v. 18, n. 2, p. 45-58, abr./jun. 2017. 
da racionalidade. Para Giarola (2011), esse problema toma forma de desvios de produção nas cooperativas de leite, o que ocorre de acordo com as oscilações no preço do leite decorrentes dos períodos de safra ou entressafra. Diante desse problema, salienta que é necessário que as cooperativas elaborem estratégias com vistas a manter a fidelidade dos cooperados. Como forma de contornar essa problemática, Giarola (2011) alerta que a falta de compartilhamento de informações é uma das causas para o surgimento dos conflitos em estudo, refletindo em uma queda na intercooperação dos associados.

Num estudo no Estado do Paraná, Bortoleto e Costa (2012) concluíram que não há efeito significativo do uso de reservas com finalidade específica para assistência técnica, educacional e social (RATES), dos gastos com educação e meio ambiente sobre a fidelidade do cooperado. Por outro, se a cooperativa possui maior capacidade de prestação de serviços e gera maiores retornos aos cooperados o comprometimento dos cooperados aumenta.

Rossés et al. (2015), por sua vez, constataram que a maioria dos associados entende fidelidade como sendo comprar os insumos e depositar a produção de soja na cooperativa. A pesquisa classificou o cooperante de acordo com sua fidelidade na entrega da produção de soja na cooperativa. O estudo revelou que $63,9 \%$ dos cooperados entrevistados foram fiéis à cooperativa quanto à entrega da soja, na safra 2012/13, 16,7\% foram moderadamente fiéis, 11,1\% foram pouco fiéis e 8,3\% foram infiéis.

O estudo de Rossés et al. (2015) mostrou que a confiança, a honestidade e a credibilidade da cooperativa, pontualidade nos pagamentos, estrutura de armazenagem, assistência técnica, prazo de pagamento dos insumos para safra (financiamento do cooperado), hábito de entregar a produção na cooperativa, distribuição das sobras líquidas conforme estatuto social e contratos de troca-troca (grão por insumos) foram os principais fatores que estimularam a fidelidade dos cooperados do caso analisado, respectivamente. Merece destaque a variável "Preço pago pela cooperativa, quando comercializo a soja" que apareceu na 20ạ posição em nível de importância. Como fatores que desestimularam a fidelidade, citam-se os descontos praticados pela cooperativa na hora da entrega da produção de soja, o preço pago pela cooperativa não é muito atrativo (muitas vezes o cooperado encontra preços mais competitivos em outros estabelecimentos), e uma agilidade maior no recebimento e descarga da soja. As variáveis envolvendo financiamento do cooperado por outras empresas e dívidas com a cooperativa, como fator inibidor da lealdade, citados por outros pesquisadores, nesse estudo não logrou significância maior. Ainda, o estudo abordou outras três variáveis que podem ser mais bem utilizadas pela cooperativa, trata-se dos incentivos econômicos à fidelidade, marketing e ajuda no frete.

\section{METODOLOGIA}

Este artigo refere-se a um Estudo de Caso realizado junto aos fornecedores de leite de uma Cooperativa. Tal organização está localizada na região Norte do Rio Grande do Sul, na cidade de Getúlio Vargas, e será chamada doravante apenas de Cooperativa X. Como procedimentos metodológicos adota-se a pesquisa bibliográfica, em dados secundários e uma pesquisa de campo, através do uso de questionário fechado e entrevista a um informante qualificado. Assim, a presente pesquisa foi desenvolvida em três fases:

a) Pesquisa em dados secundários e pesquisa bibliográfica. Essa fase teve por objetivo o levantamento de referências teóricas já analisadas e publicadas por meios escritos e eletrônicos, 
como livros, artigos científicos, páginas de web e sites (FONSECA, 2002). Essa etapa contribuiu para compor o corpo teórico do artigo e auxiliar na elaboração do questionário e entrevista.

b) Pesquisa de campo. Primeiramente foi realizada uma entrevista com informante qualificado, representado por um técnico do Departamento de Política Leiteria da Cooperativa X. Logo a seguir, foi aplicado um questionário estruturado junto aos agricultores associados. O questionário foi aplicado nos meses de setembro e outubro de 2015, com 140 associados da Cooperativa X. Essa quantidade de associados foi definida a partir do cálculo de amostra, tendo por base a população (total) de associados da cooperativa que é 290 . O cálculo utilizado foi:

$$
n=\frac{N \cdot Z^{2} \cdot p \cdot(1-p)}{Z^{2} \cdot p \cdot(1-p)+e^{2} \cdot(N-1)}
$$

Onde: $\mathrm{n}$ - amostra calculada; $\mathrm{N}$ - população; Z - variável normal padronizada associada ao nível de confiança; $p$-verdadeira probabilidade do evento; e - erro amostral.

c) Análise dos dados. A análise dos dados coletados a campo compreendeu um processo que envolveu aprofundamento e estudo, bem como análise estatística. Para a composição das questões fechadas, foi utilizado Escala de Likert que foram submetidas a análises univariadas e multivariadas utilizando-se o programa computacional PSPP. As questões abertas e demais dados secundários foram analisados de forma qualitativa.

\section{RESULTADOS E DISCUSSÕES}

Esta seção trata dos resultados obtidos através da pesquisa empírica junto aos associados e ao Departamento de Política Leiteria da Cooperativa X e a respectiva discussão destes. Dessa forma, passa-se à caracterização dos envolvidos, especificamente dos fornecedores de leite e respectivas unidades de produção.

\subsection{Caracterização dos fornecedores e seus estabelecimentos}

Dos municípios em que residem os associados fornecedores de leite entrevistados, observa-se que 35 associados moram no município de Sertão, seguidos por Erebango, Estação e Getúlio Vargas com 21\% (29 associados), 19\% (27 associados) e 19\% (27 associados), respectivamente. Quanto ao gênero dos pesquisados, $89 \%$ são do sexo masculino e $11 \%$ do sexo feminino. A maioria das associadas são viúvas ou filhas de produtores que ficaram para sucessão familiar. Acerca da escolaridade, do total de associados entrevistados, $48 \%$ não completaram o ensino fundamental, $28 \%$ possuem ensino fundamental completo e $16 \%$ o ensino médio completo. Outro dado que chama a atenção é que apenas $4 \%$ possuem ensino técnico e outros $4 \%$, graduação.

O Gráfico 1 apresenta a área dos estabelecimentos dos associados, em que se evidencia que $36 \%$ dos associados possuem menos de 20 hectares de terra. Também é importante ressaltar que $13 \%$ possuem mais de 80 hectares, sendo estes enquadrados como não familiares. Embora especificar a área das propriedades seja um fator de caracterização das propriedades, o tamanho da área não tem ligação direta com a quantidade de leite produzido no estabelecimento, já que a quantidade de leite está relacionada ao grau de intensificação técnica. 


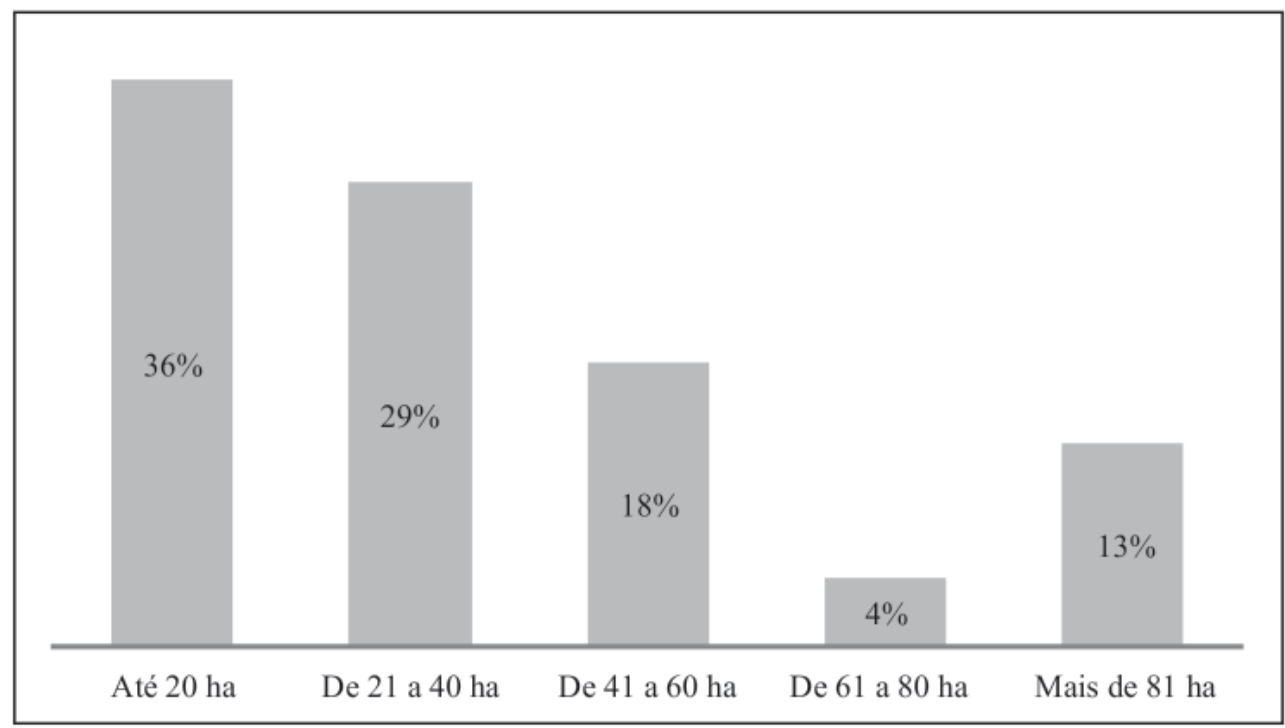

Gráfico 1 - Tamanho das propriedades dos associados fornecedores da cooperativa participantes da pesquisa.

Fonte: Elaborada pelos autores com base nos dados da pesquisa.

O Gráfico 2 esquematiza a quantidade de leite produzida mensalmente pelos 140 entrevistados. Entre as faixas de produção (as mesmas estabelecidas pela cooperativa para fins de distinção de preço do leite), destaca-se que 34\% dos associados comercializam de 6 a 12 mil litros/mês, ou seja, produzem de 200 litros/dia a 400 litros/dia. Segundo o Censo Agropecuário de 2006, no Brasil os estabelecimentos que produzem de 200 a 500 litros de leite correspondem a $2,6 \%$ e produzem $18,8 \%$ do leite nacional. O mesmo Censo aponta que a maioria dos estabelecimentos produz até 10 litros diários, mas, ao mesmo tempo, a minoria destes comercializa a produção (INSTITUTO BRASILEIRO DE GEOGRAFIA E ESTATÍSTICA [IBGE], 2016).

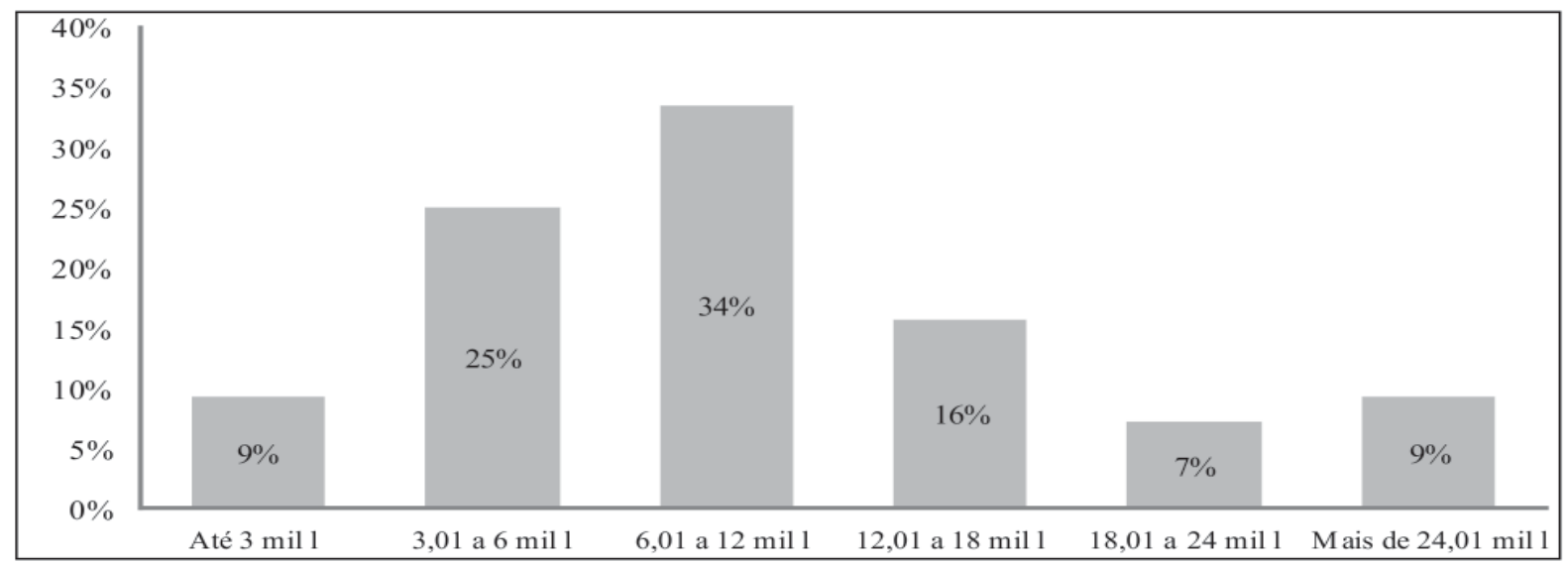

Gráfico 2 - Quantidade de leite comercializada/mês pelos associados fornecedores de leite da cooperativa participantes da pesquisa.

Fonte: Elaborada pelos autores com base nos dados da pesquisa.

\subsection{Organização da Cadeia de Suprimentos e atributos das transações}

Com relação à comercialização, obteve-se que $68 \%$ dos associados comercializam leite para a Cooperativa $\mathrm{X}$ há mais de cinco anos, mostrando uma relação de longo prazo entre associado 
versus cooperativa. Muitos desses associados entregam leite para a cooperativa desde que esta começou a coletar leite na região (em 2009).

A fim de contextualizar o nível de disputa entre empresas processadoras pelo leite dos associados participantes da pesquisa, buscou-se mapear o número de empresas, além da cooperativa, que procuraram o estabelecimento dos associados com o intuito de comprar o leite produzido nos últimos dois anos. Os resultados dessa investigação apontaram que $36 \%$ dos produtores não foram 'procurados' por nenhuma empresa concorrente nesse período. Em contrapartida, $64 \%$ já foram procurados por pelo menos uma empresa concorrente, demonstrando que as empresas adotam a estratégia de persuasão direta aos produtores, na maioria dos casos dos fornecedores pesquisados.

Para saber se há confiança entre as partes, foram ouvidos os dois agentes da transação (fornecedor e elo agroindustrial). Conforme o informante-chave da pesquisa, representante da cooperativa, esta confia em seus associados 'parcialmente'. Isso porque existem aspectos que afetaram a confiança junto aos seus associados, dos quais destaca: fraudes no leite, através da mistura de água a fim de aumentar seu volume de entrega; e o fato de o produtor ter amostras 'preparadas' para o dia de coleta de leite para os testes de Contagem Bacteriana Total (CBT) e Contagem de Células Somáticas (CCS), testes estes que têm influência direta na formação do preço pago ao produtor. Da perspectiva do produtor, 55\% afirmaram que confiam totalmente, $36 \%$ confiam na cooperativa. Por outro lado, $9 \%$ afirmam que confiam pouco na cooperativa. Os fatores que geram insegurança ao fornecedor relacionam-se com os resultados das análises de CBT e CCS. Segundo os entrevistados, os resultados desses testes variam muito de mês para mês, sendo que o manejo na ordenha e limpeza dos equipamentos é rotineiro e não existiriam motivos para as tais variações. Assim, percebe-se que o oportunismo está presente nas transações, afetando a confiança especialmente no que diz respeito à possibilidade de fraude do leite.

A Cooperativa X oferta serviços complementares ao produtor, ou seja, na transação comercial do leite não existe unicamente a entrega do produto e o pagamento monetário em troca (mercado spot). Além desse pagamento, a cooperativa oferta serviços e vantagens aos associados, quais sejam: Serviços na produção; Política de pagamento; Preço do leite; Assistência Técnica; Retorno; Reserva de domínio.

Assim, observa-se que ela realiza a coordenação da cadeia, através de uma "estrutura de governança híbrida". Nessa estrutura, acompanha todo o sistema produtivo do agricultor, desde a compra de equipamentos, insumos, assistência técnica, estímulo produtivo através do pagamento diferenciado de preço por volume e qualidade etc. Tais serviços e vantagens foram avaliados neste trabalho quanto à satisfação dos associados, como pode ser visualizado na Tabela 1.

Tabela 1 - Grau de satisfação dos associados fornecedores da cooperativa estudados quanto aos serviços que ela oferece

\begin{tabular}{cccccccc}
\hline $\begin{array}{c}\text { Condicionantes/ } \\
\text { Satisfação (\%) }\end{array}$ & $\begin{array}{c}\text { Serviços na } \\
\text { produção }\end{array}$ & $\begin{array}{c}\text { Política de } \\
\text { pagamento }\end{array}$ & $\begin{array}{c}\text { Preço do } \\
\text { leite }\end{array}$ & $\begin{array}{c}\text { Assistência } \\
\text { Técnica }\end{array}$ & $\begin{array}{c}\text { Retorno } \\
\text { Reserva de } \\
\text { domínio }\end{array}$ \\
\hline Totalmente satisfeito & 39 & 31 & 32 & 21 & 64 & 51 \\
Satisfeito & 47 & 39 & 39 & 47 & 32 & 39 \\
Pouco satisfeito & 14 & 24 & 18 & 21 & 4 & 10 \\
Insatisfeito & 0 & 6 & 11 & 11 & 0 & 0 \\
Totalmente insatisfeito & 0 & 0 & 0 & 0 & 0 & 0
\end{tabular}

Fonte: Elaborada pelos autores com base nos dados da pesquisa. 
Os 'serviços na produção' dizem respeito à comercialização de insumos e industrialização da produção adquirida. Percebe-se que acerca desse fator não há associados insatisfeitos quanto aos serviços prestados, sendo que $86 \%$ se dizem totalmente satisfeitos ou satisfeitos.

Quanto à "Política de pagamento", destaca-se que os principais determinantes do valor a ser pago relacionam-se à qualidade e à quantidade de leite, além do preço médio de mercado. Assim, a Cooperativa $X$ analisa o mercado e define um preço que deverá ser aprovado pelo conselho fiscal, que é composto por associados e direção. No que diz respeito ao pagamento pela quantidade, quanto mais leite o associado comercializar para a cooperativa, maior será o preço. Já na qualidade, quanto menores os índices de CBT e CCS, maior será o preço, sendo que também faz parte da qualidade, a quantidade de sólidos totais presentes no leite (gordura, proteína, lactose), sendo esse último fator com menor impacto no preço. O preço do leite também conta com algumas outras bonificações, como $\mathrm{R} \$ 0,02 /$ litro a mais para quem possui tanque de expansão (resfriador a granel) e $\mathrm{R} \$ 0,005 /$ litro a mais para o produtor que tem o seu rebanho livre das zoonoses tuberculose e brucelose. Com relação a esse aspecto, 31\% dos entrevistados afirmam que estão totalmente satisfeitos, $39 \%$ satisfeitos, $24 \%$ pouco satisfeitos e $6 \%$ estão insatisfeitos quanto à política de pagamento.

A satisfação dos produtores em relação ao "Preço do leite" apontou que 32\% estão totalmente satisfeitos, 39 \% satisfeitos, $18 \%$ pouco satisfeitos e 11\% insatisfeitos. Esses $11 \%$ que estão insatisfeitos alegam que o preço do leite deveria ser maior. Segundo eles, deveria ser acima de $\mathrm{R} \$ 1,00$ líquido, ou seja, já descontados o frete (varia de $5 \%$ a 11\%) e o Funrural (2,3\%). Alerta-se que o preço médio pago ao produtor pela cooperativa - quando da realização da pesquisa - estava em $\mathrm{R} \$ 0,89$. Porém, os agricultores não atribuem a culpa desse preço para a cooperativa em particular, alegam ser um problema recorrente na cadeia produtiva do leite.

Quanto ao item "Assistência técnica", todo produtor tem direito de usufruí-la através do departamento de produção de leite, que possui dois técnicos agropecuários, dois médicos veterinários e dois inseminadores. A satisfação no que diz respeito à assistência técnica, mostra que $21 \%$ dos associados estão totalmente satisfeitos; $47 \%$ estão satisfeitos, outros $21 \%$ estão pouco satisfeitos e $11 \%$ estão insatisfeitos. Os principais motivos relatados pela insatisfação são o número baixo de visitas dos técnicos nas propriedades e o fato de algumas visitas ocorrerem fora dos dias úteis, como finais de semana e feriados.

Quanto ao "Retorno" de capital ao associado referente aos lucros da cooperativa, este ocorre uma vez por ano, e o valor final é diferente para cada sócio. O valor monetário a que o associado tem direito é referente ao total de leite comercializado para a cooperativa, depende do resultado financeiro desta e das compras feitas no mercado agropecuário e no supermercado da cooperativa. Nesse quesito, $64 \%$ dos entrevistados estão totalmente satisfeitos, $32 \%$ estão satisfeitos e $4 \%$ estão poucos satisfeitos.

Por fim, destaca-se o índice de satisfação de um sistema de contrato de comodato denominado "Reserva de domínio". Diversos são os equipamentos (exemplo: resfriador, ordenhadeira canalizada e balde ao pé, gerador, silo de ração etc.) ofertados nesse sistema, em que o associado adquire o bem pagando à cooperativa de forma parcelada. Entretanto o produtor só será dono do equipamento a partir da quitação total deste, quando será emitida uma nota fiscal em seu nome. Quanto a esse serviço, 51\% estão totalmente satisfeitos, 39\% satisfeitos e $10 \%$ pouco satisfeitos. Os pouco satisfeitos acham curto o prazo de pagamento, que é de dois anos. 
Para analisar as "vantagens em fornecer para a cooperativa", os associados foram questionados acerca do que consideram mais importante na definição do agente processador para quem eles comercializarão o leite produzido em suas unidades de produção. Os resultados esquematizados na Gráfico 3 demonstram que o fator mais relevante na escolha do 'elo indústria' é o preço, citado por $20 \%$ dos associados como mais importante.

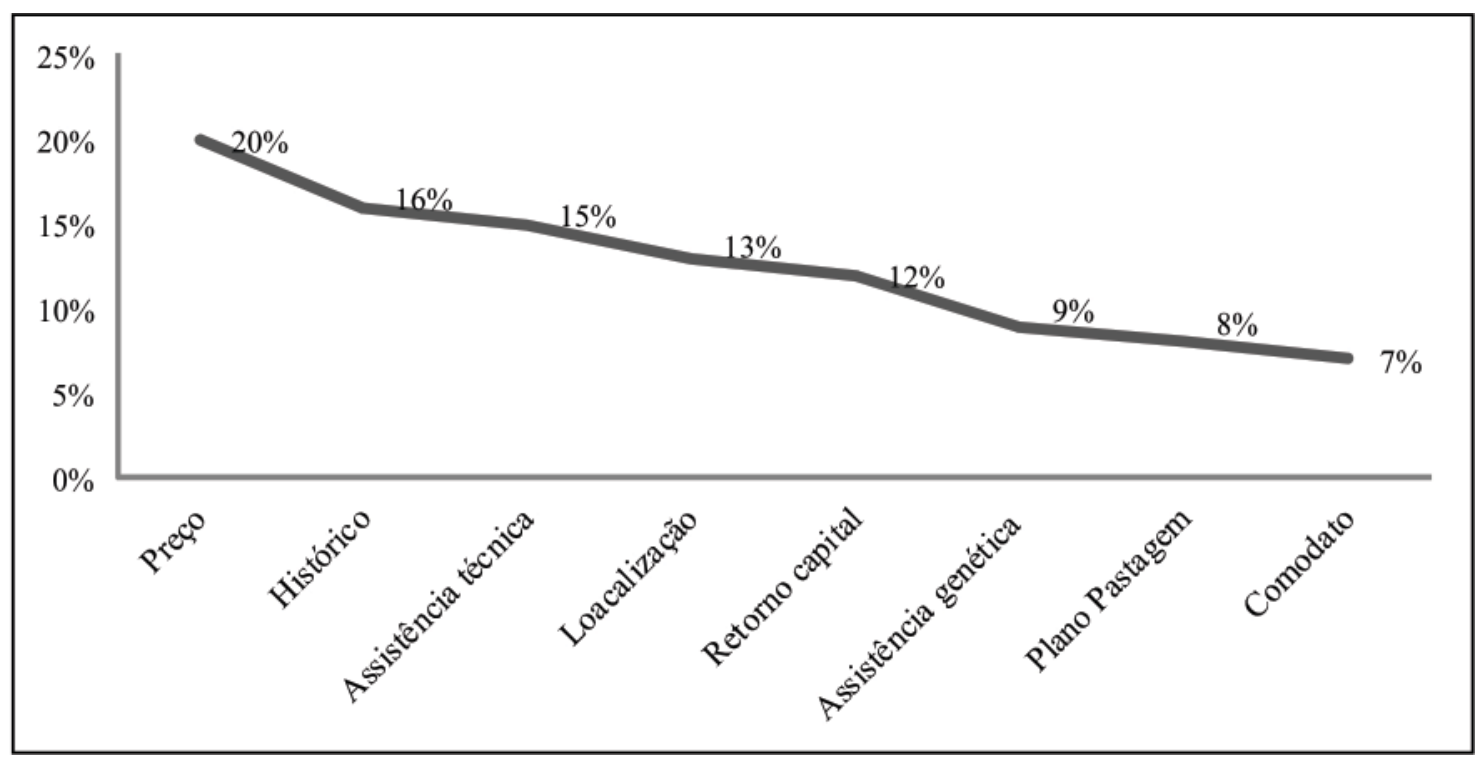

Gráfico 3 - Condicionantes que os agricultores associados da cooperativa estudados consideram mais importantes na definição de para quem eles comercializarão o leite Fonte: Elaborada pelos autores com base nos dados da pesquisa.

Também vale destacar outros fatores como o histórico da cooperativa (tradição) com 16\%, o serviço de assistência técnica (15\%), e localização da cooperativa/empresa (13\%). Os outros fatores possuem menor importância na definição dos produtores, são eles: retorno de capital (12\%), assistência em genética (9\%), plano pastagem/calcário (8\%) e o com menor importância, o sistema de comodato/reserva de domínio (7\%). Por outro lado, a cooperativa também foi questionada sobre quais motivos fazem o produtor a escolher para comercializar o leite, e não outra empresa processadora. Segundo ela, os motivos são os preços competitivos, assistência técnica e veterinária e benefícios como retorno de capital, plano pastagem/calcário.

Num estudo semelhante, Móglia et al. (2004) alertam que, na relação do cooperado com a cooperativa, deve-se considerar o interesse econômico do cooperado, motivação esta que pode preponderar em determinadas situações. Para Móglia et al. (2004), diante de um mercado altamente competitivo no setor agrícola, faz-se necessário agregar benefícios diferenciados aos associados. A cooperativa pode gerar estímulos dos mais variados e diferentes processos, desde os incentivos econômico-financeiros, tipo de concessão de bônus, até os estabelecimento de obrigatoriedade contratual nas transações. Por outro lado, afirmam que, dentre aqueles que romperam a relação de fidelidade, 18,38\% o fizeram por motivação econômica (preço maior), sendo que outras motivações de ordem econômica podem ser identificadas nas declarações de ajuda no frete $(10,65 \%)$ e financiamento ao produtor (8,26\%). Ficando evidente que a infidelidade tem origem predominantemente econômica.

A Tabela 2, por sua vez, apresenta os principais condicionantes de competitividade elencados para a presente pesquisa e como está a satisfação dos associados fornecedores de leite da 
cooperativa em relação a cada um deles. Constatou-se que para todos esses aspectos analisados, o nível de satisfação dos associados se mostrou alto.

Tabela 2 - Condicionantes de competitividade e satisfação dos associados em relação à cooperativa estudada

\begin{tabular}{ccccccc}
\hline Condicionantes (\%) & Sempre & $\begin{array}{c}\text { Quase } \\
\text { sempre }\end{array}$ & Às vezes & $\begin{array}{c}\text { Quase } \\
\text { nunca }\end{array}$ & Nunca \\
\hline Compartilhamento de informações entre & 39 & 47 & 14 & 0 & 0 \\
$\begin{array}{c}\text { cooperativa e associados } \\
\text { Divisão de lucros entre cooperativa e produtor } \\
\text { Frequência que ocorrem conflitos com a } \\
\text { cooperativa nas transações }\end{array}$ & 58 & 38 & 4 & 0 & 0 \\
$\begin{array}{c}\text { Cooperativa exige utilização de ativo fixo } \\
\text { (equipamento, maquinário etc.) }\end{array}$ & 0 & 0 & 12 & 49 & 39 \\
$\begin{array}{c}\text { Desenvolve ações de formação } \\
\text { Desenvolve ações que visam à melhoria da } \\
\text { qualidade do leite }\end{array}$ & 29 & 59 & 12 & 0 & 0 \\
\hline
\end{tabular}

Fonte: Elaborada pelos autores com base nos dados da pesquisa.

O principal instrumento de informação da Cooperativa para o associado é um informativo que possui periodicidade mensal. Esse informativo é ativo desde 1976 e tem 290 edições. Apesar de não haver problemas com o compartilhamento de informações, destacam-se as ponderações de Mendes e Passador (2015) acerca da necessidade de elevar a Educação Cooperativa como uma maneira dos associados serem mais conscientes da importância da participação e, por consequência, melhorar o desempenho da cooperativa, e, assim, a sua própria satisfação, seria fortalecida. Os autores ainda concluem que é possível dizer que níveis mais elevados de educação não garantem a mais alta Educação Cooperativa, sendo necessário investir em ações específicas para a Educação Cooperativa e para o incentivo à cooperação.

Acerca de conflitos entre a cooperativa e os associados nas transações, eles são fatores que dificultariam ou que resultariam da dificuldade de estabelecer confiança nas transações entre os agentes, o que resultaria em incertezas nas transações. Nesse caso, fica evidente que a incidência de conflitos é mínima, sendo um fator que agrega competitividade para a cooperativa e auxilia na fidelização dos fornecedores de leite.

A exigência da utilização de algum ativo fixo (equipamento), no caso da cooperativa estudada, se restringe à utilização de resfriador de leite a granel, sendo esta na verdade uma exigência da legislação. Como a cooperativa segue aspectos que determina a Normativa 62 sobre o mercado do leite, ela exigiu que seus associados adquirissem um resfriador a granel para que pudessem continuar entregando-Ihe o leite. Como muitos associados possuíam tanque de imersão, tiveram que adquirir tanque de expansão. Portanto as exigências não são específicas da cooperativa, mas da legislação nacional. Aparentemente a questão da especificidade de ativos, em particular para o fornecimento para cooperativa não se mostra relevante.

As ações de formação, através de palestras, cursos, visitas técnicas que a entidade provê a seus fornecedores, pode ser um fator de diferenciação positiva e, consequentemente, somaria na fidelização do fornecedor. Essas ações de melhoria se dão, especialmente, a partir da assistência técnica direcionada, do repasse de informações qualificadas para o agricultor e de capacitações.

Por fim, aborda-se a opinião dos produtores quanto à importância de uma relação de longo prazo com parceiros comerciais. Essa relação contribuiria para redução de assimetrias de 
informação entre os agentes comerciais, bem como para a redução da incerteza de transações e inibiria o comportamento oportunista das partes.

A maioria dos associados classificou esse fator como muito importante ou importante. Para 79\% a frequência das transações assume um papel primordial quando da escolha do comprador do leite, demonstrando que esse aspecto abordado pela ECT também se confirma no presente estudo. Para $7 \%$ esse fator é pouco importante e para $14 \%$ tal condicionante é importante eventualmente.

Esse contexto de resultados demonstra tanto o nível de satisfação dos agricultores em relação à cooperativa, quanto o perfil comportamental diante das relações transacionais estabelecidas entre esses agentes. Observa-se que os agricultores, associados da cooperativa, demandam dela um conjunto de ações e serviços no sentido de qualificar a transação estabelecida entre eles- que são os fornecedores de leite- e a cooperativa- que vai comprar e processar a produção. Porém, em contrapartida, mesmo a cooperativa operando com um conjunto de serviços para agregar valor à transação, os associados permanecem considerando o preço como fator principal para escolha da organização para a qual comercializarão a produção.

Esse comportamento, além de indicar a não fidelização dos associados, também aponta um comportamento oportunista. O resultado encontrado nesta pesquisa contrapõe-se à pesquisa realizada por Rossés et al. (2015) em que o fator preço aparece na 20a posição entre as ações afirmativas de 'fidelização' dos associados.

\section{CONCLUSÃO}

Nesta pesquisa, buscou-se identificar os diferenciais competitivos do ponto de vista do agricultor/fornecedor que interferem na tomada de decisão quanto à comercialização do leite para uma cooperativa de laticínios em detrimento de outras empresas processadoras. Foi possível verificar que as vantagens da cooperativa em relação aos concorrentes, sob o ponto de vista do associado, concentram-se na oferta de serviços e na assistência técnica, retorno dos resultados financeiros e descontos em investimentos em genética. Porém esses fatores se agregam a um preço competitivo comparativamente às demais empresas processadoras.

Destaca-se que, caso o preço seja significativamente abaixo das demais organizações, esses fatores citados, isoladamente ou em conjunto, não serão suficientes para que os agricultores optem pela cooperativa quando da comercialização da produção. Portanto, o preço é o principal condicionante de decisão do agricultor e, necessariamente, as cooperativas precisam ter preço competitivo com as demais empresas processadoras. Porém, se quiserem fidelizar o agricultor, estabelecer relação de longo prazo e se destacar competitivamente, ações/serviços adicionais precisam ser incorporadas(os), como esses destacados anteriormente.

Dessa forma, observa-se que, mesmo dispondo de diferenciais (serviços, divisão de recompensas, etc.) que propiciam um relacionamento de longo prazo, buscando reduzir as incertezas, mantendo a frequência das transações, os produtores, ao apontarem o preço como fator sine qua non nas negociações, deixam transparecer um comportamento oportunista. Ou seja, todos os 'diferenciais' em termos de relacionamento estabelecidos com os forncedores, que na verdade são sócios da cooperativa, não são fortes o suficiente para se destacar em relação ao atributo concorrencial preço. Nesse sentido, caso o preço oferecido pelo leite na cooperativa seja inferior ao ofertado pelas empresas privadas, os associados tendem a migrar para realizar as transações comerciais com as empresas privadas. 


\section{REFERÊNCIAS}

ALBUQUERQUE, L. G. Competitividade em recursos humanos. Revista de Administração, São Paulo, v. 27, n. 4, p. 16-29, 1992.

ARBAGE, A. P. Custos de transação e seu impacto na formação e gestão da cadeia de suprimentos: estudo de caso em estruturas de governança híbridas do sistema agroalimentar no Rio Grande do Sul. 2004. Tese (Doutorado em Administração)- Universidade Federal do Rio Grande do Sul, Porto Alegre, 2004.

BALLOU, R. Bussiness logistics: supply chain management. New Jersey: Prentice Hall, 2004.

BETH, S.; BURT, D.N.; COPACINO, W.; GOPAL, C.; LEE, H.L; LYNCH, R.P.; MORRIS, S. Desafios da cadeia de suprimentos: construindo relacionamentos. In: Gestão da cadeia de suprimentos. 2. reimp. Tradução de Ricardo Bastos. Rio de Janeiro: Elsevier, 2008.

BRANDÃO, J. B. A gestão da cadeia de suprimentos das redes regionais de varejo de frutas, legumes e verduras no Rio Grande do Sul. 2011. Tese (Doutorado em Extensão Rural)- Universidade Federal de Santa Maria, Santa Maria, RS, 2011.

BREITENBACH, R.; SOUZA, R. S. Estrutura, conduta e governança na cadeia produtiva do leite: um estudo multicaso no Rio Grande do Sul. Revista Eletrônica de Administração REAd, Porto Alegre, RS, edição 82, n. 3, p. 750-78, set./dez. 2015.

BORTOLETO, F. C.; COSTA, D. R. M. Responsabilidade social e fidelidade: um estudo para cooperativas agropecuárias. In: CONGRESSO DA SOBER, 50., 2012. Anais... Vitória, ES, 2012.

CANZIANI, J. R. Cadeias agroindustriais: o programa empreendedor rural. Curitiba: SENAR-PR, 2003.

FONSECA, J. J. S. Metodologia da pesquisa científica. Fortaleza, CE: UEC, 2002. Apostila.

GIAROLA, E. A fidelização dos associados nas cooperativas de leite: uma análise sob a perspectiva da teoria dos jogos e da social network analysis. In: INTERNATIONAL CONFERENCE ON INDUSTRIAL ENGINEERING AND OPERATIONS MANAGEMENT, 17. Belo Horizonte, Brazil, 4 to 7 October, 2011. Disponível em: <http:// www.abepro.org.br/biblioteca/enegep2011_ti_st_141_891_18226.pdf>.

GRAEF, N. D.; BUTTENBENDER, P. L.; WEISNER, A.; SPAREMBERGER, A.; ZAMBERLAN, L.; HOFLER, C. E. Inovações tecnológicas nas cadeias do agronegócio de alimentos da região fronteira noroeste do Rio Grande do Sul. In: SIMPOSIO IBEROAMERICANO EM COMÉRCIO INTERNACIONAL, DESENVOLVIMENTO E INTEGRAÇÃO REGIONAL, 2., 2009, Santa Rosa, RS. Anais... Ijuí, RS: Ed. Unijuí, 2009. v. 1, p. 1-15.

INSTITUTO BRASILEIRO DE GEOGRAFIA E ESTATÍSTICA (IBGE). Pesquisa Pecuária Municipal. 2016. Disponível em: $<w w w . i b g e . g o v . b r / h o m e / e s t a t i s t i c a / p e s q u i s a s / p e s q u i s a \_r e s u l t a d o s . p h p ? i d \_p e s q u i s a=21>$. Acesso em: 10 jan. 2016.

MENDES, J. T. G.; PADILHA JUNIOR, J. B. Agronegócio: uma abordagem econômica. São Paulo: Pearson Prentice Hall, 2007.

MENDES, M. M.; PASSADOR, C. S. The role of cooperative education and of the participation of members in the performance of the cooperative: case study of a Brazilian agricultural cooperative. 2015. Disponível em: <https://www.researchgate.net/publication/264883410_The_role_of_cooperative_education_ and_of_the_participation_of_members_in_the_performance_of_the_cooperative_case_study_of_a_ Brazilian_agricultural_cooperative>. Acesso em: jun. 2016.

MÓGLIA, L. C.; PARADA JÚNIOR, I.; BIALOSKORSKI NETO, S.; MARCHI, D. Fidelidade e reciprocidade do cooperado: o caso da Carol. In: CONGRESSO DA SOBER, 42., 2004, Cuiabá. Anais... Cuiabá: UFMT, 2004.

ROSSÉS, G. F.; TOMAZI, M., STECCA, F. L. P. A. OLIVEIRA, D. O. SCCOTT, C. R. da C. Fidelidade em cooperativa agropecuária: um estudo de caso. Revista de Gestão e Organizações Cooperativas - RGC, Santa Maria, RS, v. 2, n. 4, jul./dez. 2015.

UNITED STATES DEPARTMENT OF AGRICULTURE (USDA). Foreign agricultural service. [s.d.]. Disponível em: <http//apps.fas.usda.gov/pdsonline/>. Acesso em: 10 abr. 2016. 
VASCONCELLOS, M. A. S.; GARCIA, M. H. Fundamentos de Economia. 2. ed. São Paulo: Saraiva, 2006.

WILLIAMSON, O. E. Las instituciones económicas del capitalismo. México: Fondo de Cultura Economica, 1989.

\section{Sobre os autores:}

Raquel Breitenbach: Bacharel em Desenvolvimento Rural e Gestão Agroindustrial, Mestre e Doutora em Extensão Rural, Professora do Instituto Federal de Educação, Ciência e Tecnologia do Rio Grande do Sul (IFRS).E-mail: raquel.breitenbach@sertao.ifrs.edu.br

Janaína Balk Brandão: Doutora em Extensão Rural, Professora da Universidade Federal do Pampa (UNIPAMPA). E-mail: janainabalkbrandao@gmail.com

Marcelo Zorzan: Tecnólogo em Agronegócio. Instituto Federal de Educação, Ciência e Tecnologia do Rio Grande do Sul (IFRS). E-mail: Marcelo.Zorzan@coopsantaclara.com.br 